BMJ Open Diabetes Research \& Care

\section{Coronary artery disease in patients with atypical chest pain with and without diabetes mellitus assessed with coronary CT angiography}

To cite: Krul MMG, Bogaard K, Knol RJJ, et al. Coronary artery disease in patients with atypical chest pain with and without diabetes mellitus assessed with coronary CT angiography. BMJ Open Diabetes Research and Care 2014;2:000004. doi:10.1136/ bmjdrc-2013-000004

MMGK and KB contributed equally.

Received 18 November 2013 Revised 26 February 2014 Accepted 26 March 2014

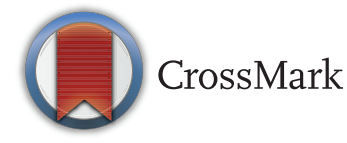

${ }^{1}$ Department of Cardiology, Medical Center Alkmaar, Alkmaar, The Netherlands ${ }^{2}$ Department of Cardiology, Rijnland Hospital, Leiderdorp, The Netherlands

${ }^{3}$ Department of Nuclear Medicine, Medical Center Alkmaar, Alkmaar, The Netherlands ${ }^{4}$ Department of Cardiology, vU Medical Center, Amsterdam, The Netherlands

Correspondence to Marije MG Krul; marijekrul@hotmail.com

\section{ABSTRACT}

Introduction: Coronary artery disease (CAD) in diabetes mellitus (DM) is often widespread when diagnosed. Non-invasive coronary calcium scoring and coronary CT angiography (CAC-score/CCTA) are accurate in the detection of CAD. This study compared CAD characteristics as identified by CCTA between patients with and without DM with atypical chest pain. Methods: CAD was defined as CAC-score $>0$ and/or presence of coronary plaque. Several CAD characteristics (number of affected segments, obstructive ( $>50 \%$ stenosis) CAD and CAD distribution) were compared on a per patient and segment basis. Subanalysis of duration of DM ( $<5$ or $>5$ years) and gender was performed.

Results: A total of 1148 patients $(63.3 \%$ men, mean age $57.7 \pm 10.7)$, of whom $99(8.6 \%)$ suffered from DM, were referred for CCTA. There was no difference in the prevalence of CAD between patients with and without DM (53.5\% vs $50.9 \%, p=0.674)$. However patients with DM showed more affected coronary segments compared with patients without DM $(2.5 \pm 3.4$ vs 1.7 $\pm 2.4, p=0.003$ ). Multivariate analysis indicated that DM was an independent predictor of obstructive CAD (OR $2.16,95 \% \mathrm{Cl} 1.23$ to 3.78 ), as were age, women, and Diamond-Forrester score. In our study, obstructive CAD was more prevalent in women than in men (DM $40.0 \%$ vs $14.1 \%, p=0.003$; non-DM $16.8 \%$ vs $8.4 \%$, $p<0.001$ ). Patients suffering from $D M>5$ years showed more distal plaques ( $11.2 \%$ vs $7.7 \%, p=0.030)$.

Conclusions: Patients with atypical chest pain and DM showed more extensive CAD, as well as more obstructive CAD, particularly in women. Diabetes duration ( $>5$ years) was not associated with more obstructive coronary disease or different plaque morphology, although more distal disease was present.

\section{INTRODUCTION}

The number of people with diabetes mellitus (DM) is increasing due to population growth, aging, urbanization, increasing prevalence of obesity, and physical inactivity, with an estimated number of 200 million patients worldwide. ${ }^{1}$ Patients with DM have a

\section{Key messages}

- Approximately $50 \%$ of middle-aged individuals with cardiovascular risk factors presenting with atypical chest pain will have previously undiagnosed coronary artery disease (CAD); presence of diabetes history does not affect this relationship.

- Patients with diabetes mellitus (DM) showed more affected coronary segments and more obstructive CAD than patients without DM.

- Obstructive CAD was detected more frequently in women with DM, as compared with men with DM.

- Duration of DM ( $>5$ years) is associated with the occurrence of distal plaques.

twofold to fourfold likelihood of developing coronary artery disease (CAD) with marked morbidity and mortality. ${ }^{2} \mathrm{CAD}$ in patients with DM is often more advanced at the time of diagnosis compared with patients without DM. ${ }^{34}$

Non-invasive cardiac imaging for the detection of CAD has evolved rapidly in the past decades. Coronary CT angiography (CCTA) offers detailed information on the extent and morphology of CAD. CCTA combined with coronary calcium scoring (CAC-score) is sensitive and specific in the detection of $\mathrm{CAD}$ and has been validated extensively. ${ }^{5}$ The real strength of CCTA is the exclusion of CAD in patients with a low-to-intermediate cardiovascular risk profile, and for this particular indication, there is a broad endorsement from international societies. ${ }^{6}$ Owing to technological improvements of CCTA, the radiation dose per patient has been reduced to acceptable levels. The latest generation scanners produce submillisievert $(\mathrm{mSv})$ scans without compromising image quality. ${ }^{7}$

The aim of the present study was to compare characteristics of CAD in patients 
with atypical chest pain with and without DM using a CCTA scanner of the latest generation, and to investigate the relationship between CAD and the duration of DM.

\section{METHODS}

\section{Study design}

Consecutive patients with atypical chest pain, referred for CCTA to exclude CAD at the Medical Center Alkmaar (MCA) were entered in a database prospectively between December 13, 2011 and March 08, 2013. Patients were categorized in two groups, either with or without known DM. Type 1 and 2 DM were included. DM was diagnosed according to the American Diabetes Association criteria: fasting glucose level of $\geq 7 \mathrm{mmol} / \mathrm{L}$, symptoms of DM and casual plasma glucose of $\geq 11.1 \mathrm{mmol} / \mathrm{L}$, or the need for oral hypoglycemic agents or insulin. ${ }^{8}$ Only patients in sinus rhythm and without contraindications to CCTA were included. Other exclusion criteria were a history of CAD, myocardial infarction (MI), and/or revascularization procedures. All patients gave written informed consent.

The following patient characteristics were recorded: general data such as age and gender, a full cardiovascular risk profile, active medication use, Duke risk score calculation, ${ }^{9}$ and the Diamond-Forrester risk score calculation. ${ }^{10}$ Positive family history of premature $\mathrm{CAD}$ was defined as the presence of CAD in first-degree relatives younger than 55 (men) or 65 (women) years of age. ${ }^{11}$ Smoking was defined as nicotine misuse within the previous 5 years. Hypertension was defined as a systolic blood pressure above $140 \mathrm{~mm} \mathrm{Hg}$ and/or a diastolic blood pressure above $90 \mathrm{~mm} \mathrm{Hg}$ or the use of antihypertensive drugs. ${ }^{12}$ High cholesterol was defined as a total cholesterol $>5.0 \mathrm{mmol} / \mathrm{L}$ or the use of lipid-lowering therapy. ${ }^{13}$ The duration of DM was categorized in two groups $(<5$; $>5$ years). Furthermore, differences between women and men were analyzed.

\section{Patient preparation}

CCTA was performed under fasting conditions. Medication could be used normally, with the exception of metformin (in case estimated glomerular filtration rate (eGFR) $<60 \mathrm{~mL} / \mathrm{min}$ ) and sildenafil. To prevent contrast-induced nephropathy, patients with an eGFR between 30 and $60 \mathrm{~mL} / \mathrm{min}$ received volume expansion therapy, using $0.9 \% \mathrm{NaCl}$ intravenously, before and after CCTA according to the local hospital safety protocol. In case of a heart rate above $60 \mathrm{bpm}, 100 \mathrm{mg}$ atenolol was given orally $1 \mathrm{~h}$ prior to the CCTA. Additionally, up to $30 \mathrm{mg}$ metoprolol was administered intravenously to decrease the heart rate if the heart rate still exceeded $60 \mathrm{bpm}$. Each patient also received two doses of $0.4 \mathrm{mg}$ nitroglycerin sublingually.

\section{CAC-score and CCTA data acquisition}

All scans were performed with a dual source 128-slice (Somatom Definition Flash; Siemens Medical Systems,
Erlangen, Germany). A 10-15 mL test bolus containing non-ionic low-osmolar iodinated radiocontrast (iopromide) was injected, followed by a flush of $40 \mathrm{~mL}$ saline, both at a flow rate of $6 \mathrm{~mL} / \mathrm{s}$. The time point of maximal contrast enhancement in the ascending aorta at the level of the pulmonary trunk was recorded, and an additional delay of $5 \mathrm{~s}$ was added to define the optimal time point for acquisition of coronary artery data. A dual-head injector then injected $48-75 \mathrm{~mL}$ contrast depending on $\mathrm{kV}$ used for the high-pitch flash scan and $75 \mathrm{~mL}$ in case of prospective or retrospectively triggered scan, followed by $45 \mathrm{~mL} 30 / 70 \%$ contrast/saline solution at a flow rate of $6 \mathrm{~mL} / \mathrm{s}$.

The tube voltage $(80,100$, or $120 \mathrm{kV})$ and tube current were determined automatically by the scanning system based on body geometry. ${ }^{14}$ In this study, the total radiation dose of test bolus, topogram, CAC-score, and CCTA was used to estimate the effective radiation dose for each patient.

\section{CAC-score and CCTA image analysis}

All scans were read by two physicians, who are level 2 accredited by the Society of Computed Cardiovascular Tomography (SCCT).

For CAC-score, coronary calcifications were defined as dense lesions in coronary arteries with densities $>130$ Hounsfield units. Calcifications were manually assigned to coronary arteries and added to the Agatston score for each patient. ${ }^{15}$ Agatston scores were divided into three groups: a CAC-score between 0-100, 101-400, and more than 400.

Plaque characteristics were compared on a per patient and segment basis. Coronary arteries were divided into 18 segments according to the SCCT guidelines. ${ }^{16}$ Each segment was scored for the presence of coronary plaques. Structures $>1 \mathrm{~mm}^{2}$ within and/or adjacent to the coronary artery lumen, which could be clearly distinguished from the vessel lumen, were scored as a coronary plaque. ${ }^{17}$ One coronary plaque was scored per coronary segment. Each coronary plaque was quantified for stenosis by visual estimation. The severity of stenosis was categorized $(<25 \% ; 25-49 \%$; 50-69\%; 70-99\%; $100 \%)$. A stenosis of $>50 \%$ was considered to be obstructive. The number of coronary segments with nonobstructive as well as obstructive plaques was determined for each patient. The morphology of a coronary plaque was categorized as calcified, non-calcified, or mixed lesion.

CAD was determined as CAC-score $>0$ and/or any coronary plaque. CAC-score $=0$ and no coronary plaques was defined as no CAD.

To compare the distribution of coronary plaques between patients with and without DM, patients were stratified by the location/distribution of atherosclerosis in either proximal or distal segments. The left main artery and proximal segments of the left anterior descending (LAD), right coronary artery (RCA), and ramus circumflexus (RCX) were assigned to the proximal 
Table 1 Baseline, CAC-score and CCTA characteristics of study population with and without DM

\begin{tabular}{|c|c|c|c|}
\hline Variable & DM $(n=99)$ & Non-DM $(n=1049)$ & p Value \\
\hline \multicolumn{4}{|l|}{ Demographic } \\
\hline Age (years) & $58.6 \pm 9.9$ & $57.7 \pm 10.8$ & 0.435 \\
\hline Sex (\% male) & $64(64.6)$ & $663(63.2)$ & 0.776 \\
\hline Duration of DM (years) & $6.6 \pm 6.9$ & $0 \pm 0$ & \\
\hline \multicolumn{4}{|l|}{ Risk factors } \\
\hline Hypertension & $73(73.7)$ & $676(64.4)$ & 0.063 \\
\hline Dyslipidemia & $86(86.9)$ & $823(78.5)$ & 0.049 \\
\hline Obesity (BMI $\geq 30$ ) & $43(43.4)$ & 188 (17.9) & 0.001 \\
\hline Smoking & 19 (19.2) & $213(20.3)$ & 0.792 \\
\hline Family history of CAD & $53(53.5)$ & $518(49.4)$ & 0.429 \\
\hline $\mathrm{SBP}(\mathrm{mm} \mathrm{Hg})$ & $138.8 \pm 17.4$ & $133.1 \pm 17.2$ & 0.678 \\
\hline $\mathrm{DBP}(\mathrm{mm} \mathrm{Hg})$ & $81.2 \pm 12.4$ & $80.7 \pm 11.5$ & 0.833 \\
\hline LDL cholesterol (mmol/L) & $2.9 \pm 1.1$ & $3.6 \pm 1.0$ & 0.770 \\
\hline HDL cholesterol (mmol/L) & $1.2 \pm 0.3$ & $1.4 \pm 0.4$ & 0.003 \\
\hline Total cholesterol(mmol/L) & $4.9 \pm 1.4$ & $5.7 \pm 1.1$ & 0.060 \\
\hline $\mathrm{HbA} 1 \mathrm{c}(\mathrm{mmol} / \mathrm{L})$ & $7.2 \pm 1.1$ & $5.7 \pm 0.4$ & 0.001 \\
\hline \multicolumn{4}{|l|}{ Duke score } \\
\hline Low risk & $36(36.4)$ & $599(57.1)$ & 0.001 \\
\hline Intermediate risk & $56(56.5)$ & $425(40.5)$ & 0.002 \\
\hline High risk & $7(7.1)$ & $26(2.4)$ & 0.007 \\
\hline Diamond-Forrester score & $39.5 \pm 21.6$ & $38.2 \pm 22.2$ & 0.562 \\
\hline \multicolumn{4}{|l|}{ Medication } \\
\hline ACE-I/ARB & $43(43.4)$ & $238(22.7)$ & 0.001 \\
\hline Aspirin & $41(41.4)$ & $357(34.0)$ & 0.140 \\
\hline$\beta$-blocker & $52(52.5)$ & $437(41.7)$ & 0.037 \\
\hline Statin & $64(64.6)$ & 345 (32.9) & 0.001 \\
\hline \multicolumn{4}{|l|}{ Technical data } \\
\hline Heart rate (bpm) & $61.0 \pm 7.4$ & $57.1 \pm 7.0$ & 0.001 \\
\hline Radiation dose (mSv) & $3.8 \pm 2.7$ & $2.2 \pm 1.8$ & 0.001 \\
\hline \multicolumn{4}{|l|}{ CCTA } \\
\hline CAC-score & $118 \pm 270.7$ & $73.5 \pm 209.3$ & 0.049 \\
\hline $0-100$ & $74(74.7)$ & $866(82.6)$ & 0.057 \\
\hline $101-400$ & 19 (19.2) & 125 (11.9) & 0.037 \\
\hline$>400$ & $6(6.1)$ & $58(5.5)$ & 0.826 \\
\hline Normal/no plaque & $46(46.5)$ & $515(49.1)$ & 0.617 \\
\hline CAD & $53(53.5)$ & $534(50.9)$ & 0.674 \\
\hline Obstructive CAD & $23(23.2)$ & $121(11.5)$ & 0.001 \\
\hline Non-obstructive CAD & $30(30.3)$ & $413(39.4)$ & 0.076 \\
\hline \multicolumn{4}{|l|}{ Segments } \\
\hline Number of diseased segments & $2.5 \pm 3.4$ & $1.7 \pm 2.4$ & 0.003 \\
\hline Number of segments with obstructive plaques & $0.4 \pm 1.0$ & $0.2 \pm 0.6$ & 0.001 \\
\hline Number of segments with non-obstructive plaques & $2.0 \pm 2.8$ & $1.5 \pm 2.1$ & 0.022 \\
\hline Number of diseased segments LM & $0.2 \pm 0.4$ & $0.1 \pm 0.3$ & 0.114 \\
\hline Number of diseased segments RCA & $0.7 \pm 1.1$ & $0.4 \pm 0.8$ & 0.008 \\
\hline Number of diseased segments LAD & $1.1 \pm 1.4$ & $0.8 \pm 1.1$ & 0.053 \\
\hline Number of diseased segments RCX & $0.6 \pm 1.0$ & $0.3 \pm 0.7$ & 0.001 \\
\hline
\end{tabular}

group. Mid and distal segments of LAD, RCA, and RCX and all evaluable other coronary branches were assigned to the distal group.

\section{Statistical analysis}

Continuous variables are presented as mean \pm SD and categorical variables as frequencies with percentages.
One-sample Kolmogorov-Smirnov tests were used to test continuous data for normal distribution. Between groups, differences in mean values were tested for statistical differences with two-sample $\mathrm{t}$ tests and Mann-Whitney tests, when appropriate. Pearson $\chi^{2}$ tests were used to test dichotomous parameters. To determine the relationship between plaque characteristics 
Table 2 Baseline characteristics of patients with DM with and without CAD

\begin{tabular}{|c|c|c|c|}
\hline Variable & $\begin{array}{l}\text { DM with } \\
\text { CAD } \\
(n=53)\end{array}$ & $\begin{array}{l}\text { DM without } \\
\text { CAD } \\
(n=46)\end{array}$ & p Value \\
\hline \multicolumn{4}{|l|}{ Demographic } \\
\hline Age (years) & $62.1 \pm 9.2$ & $54.5 \pm 9.2$ & 0.718 \\
\hline Sex (\% male) & $29(54.7)$ & $35(76.1)$ & 0.027 \\
\hline $\begin{array}{l}\text { Duration of DM } \\
\text { (years) }\end{array}$ & $7.1 \pm 7.4$ & $6.0 \pm 6.3$ & 0.468 \\
\hline \multicolumn{4}{|l|}{ Risk factors } \\
\hline Hypertension & $29(54.7)$ & $17(37.0)$ & 0.077 \\
\hline Dyslipidemia & $50(94.3)$ & 36 (78.3) & 0.018 \\
\hline Obesity (BMI $\geq 30$ ) & $20(37.7)$ & $20(43.5)$ & 0.220 \\
\hline Smoking & $8(15.1)$ & $11(23.9)$ & 0.266 \\
\hline Family history of CAD & $28(52.8)$ & $25(54.3)$ & 0.880 \\
\hline \multicolumn{4}{|l|}{ Medication } \\
\hline ACE-I/ARB & $28(52.8)$ & $15(32.6)$ & 0.043 \\
\hline Aspirin & $26(49.1)$ & $15(32.6)$ & 0.098 \\
\hline$\beta$-blocker & $30(56.6)$ & $22(47.8)$ & 0.383 \\
\hline Statin & 39 (73.6) & $25(54.3)$ & 0.046 \\
\hline \multicolumn{4}{|l|}{ Technical data } \\
\hline Heart rate (bpm) & $59.3 \pm 6.6$ & $62.7 \pm 8.0$ & 0.849 \\
\hline Radiation dose (mSv) & $3.6 \pm 2.9$ & $4.0 \pm 2.6$ & 0.640 \\
\hline
\end{tabular}

and DM, logistic regression analyses were performed when the dependent variable was dichotomous. When the dependent variable was continuous, linear regression analyses were performed. Univariate analyses were performed using demographic variables, classical risk factors, risk scoring systems, and medication used (variables specified in table 1). Multivariable analyses were performed with variables that were significant in univariate analyses. $p$ Values $<0.05$ were considered significant. The Duke risk score was not analyzed in the univariate and multivariate analyses because DM is one of the parameters in this particular score. The Diamond-Forrester score, not using DM as a parameter, was used instead. For the detailed per segment analysis, the unit of measure was each coronary segment and there were no adjustments or corrections made for the serial correlation between segments. Statistical Package for Social Sciences V.20 (SPSS Inc, Chicago, Illinois, USA) was used.

\section{RESULTS}

\section{Study population}

A total of 1176 patients with atypical chest pain were enrolled in the study, of which 28 patients were excluded. Twenty-three patients were excluded due to a history of $\mathrm{CAD}$, MI, and/or revascularization procedures. Five patients suffered from arrhythmias during scan acquisition which resulted in unacceptable image quality, and thus, these patients were excluded. Table 1 summarizes the characteristics of patients with and without DM at the time of the CCTA. In total, 1148 patients $(727(63.3 \%)$ men; age (mean 57.7 years \pm 10.7$)$ ) were included, of whom $99(8.6 \%)$ were patients with known DM (mean 6.6 years \pm 6.9 ). Of the study population, $95.4 \%$ had a low-to-intermediate probability for CAD according to their Duke risk score $(92.9 \%$ DM vs 97.9\% non-DM, $\mathrm{p}=0.007$ ). Patients with $\mathrm{DM}$ were more frequently obese and used more ACE-I/angiotensin receptor blocker, $\beta$-blocker, and statin therapy and had lower high-density lipoprotein levels ( $p$ values 0.001 , $0.001,0.037,0.001$, and 0.003 , respectively). Table 2 compares the clinical and radiographic characteristics of patients with DM who did or did not have CAD. Patients with DM without CAD were more often of the male gender, showed less frequent dyslipidemia, and used less statin therapy ( $\mathrm{p}$ values $0.020,0.018$, and 0.046 , respectively). None of the other measured clinical variables differed between patients with $\mathrm{DM}$ with or without $\mathrm{CAD}$.

\section{CAD on CCTA}

Coronary plaque characteristics on CCTA in patients with and without DM are shown in table 1. A normal CCTA was found in $561(48.9 \%)$ patients, with no significant difference in prevalence between patients with and without DM ( $p=0.617)$. Patients with DM had a significantly higher CAC-score than patients without DM (118 \pm 270 vs $73 \pm 209, \mathrm{p}=0.049$ ). Patients with $\mathrm{DM}$ had a significantly higher percentage of CAC-scores between 101 and $400(19 \%$ vs $11.9 \%, \mathrm{p}=0.037)$. Obstructive $\mathrm{CAD}$ was observed in $144(12.5 \%)$ patients and more frequently in patients with DM $(23.2 \%$ vs $11.5 \%, \mathrm{p}<0.001)$. Higher CAC-scores were detected in patients with obstructive CAD $(287.3 \pm 332.9$ vs $47.2 \pm 173.4, \mathrm{p}<0.001)$. The average number of diseased segments was higher in patients with DM compared with patients without DM ( $\mathrm{p}=0.003)$. The number of segments with obstructive CAD plaques was higher in patients with DM compared with patients without DM. In patients with $\mathrm{DM}$, the average number of diseased segments in the RCA $(p=0.008)$ and RCX $(p<0.001)$ was higher than in patients without DM. The difference in the average amount of diseased segments in the LAD did not reach statistical significance ( $\mathrm{p}=0.053)$.

Figure 1 shows the prevalence of obstructive CAD across the subgroup gender. Women had an overall higher prevalence of obstructive $\mathrm{CAD}$ than men. In patients with DM, $40 \%$ of the women demonstrated obstructive CAD compared with $14.1 \%$ of the men ( $p=0.003$ ). In patients without DM, $16.8 \%$ of the women compared with $8.4 \%$ of the men showed obstructive CAD $(\mathrm{p}<0.001)$.

\section{Relationship of CAD characteristics on CCTA and DM}

The results of the univariate and mulitivariate analyses of the correlation between plaque characteristics on CCTA and the presence of DM are listed in table 3 . After correction for baseline characteristics, DM proved 


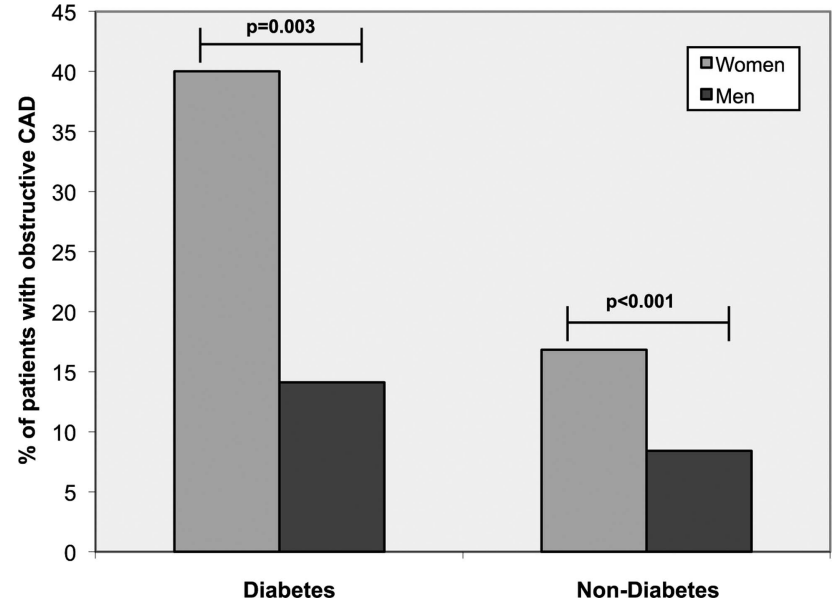

Figure 1 Prevalence of obstructive coronary artery disease (CAD) across the different diabetes mellitus and gender subgroups.

to be an independent predictor of the total number of segments with plaque $(\mathrm{p}=0.016)$. The other independent predictors of the total number of segments with plaque were age $(\mathrm{p}<0.001)$, women $\quad(\mathrm{p}<0.001)$, Diamond-Forrester score $(\mathrm{p}<0.001)$, and hypertension $(p=0.023)$. Furthermore, DM was an independent predictor of the presence of obstructive plaque (OR 2.16, $95 \% \mathrm{CI} 1.23$ to 3.78 ), as were age (OR $1.04 ; 95 \% \mathrm{CI}$ 1.02 to 1.07 ), women (OR 4.95; $95 \%$ CI 2.96 to 8.28 ), and Diamond-Forrester score (OR 1.02; 95\% CI 1.00 to 1.03). DM was also an independent predictor of the number of segments with plaque in the distal segments $(\mathrm{p}=0.010)$, as were age $(\mathrm{p}<0.001)$, women $(\mathrm{p}<0.001)$, and Diamond-Forrester score $(\mathrm{p}=0.008)$.

\section{Per segment analysis}

A total of 17240 segments were identified in the study population. After exclusion of $105(0.61 \%)$ segments due to non-diagnostic image quality, a total of 17135 coronary segments were included in the analysis. In the remaining 17135 segments, 1998 (11.7\%) segments contained plaque. Of the 17135 segments, there were $243(1.4 \%)$ segments with obstructive plaque, (44 of $1471(3.0 \%)$ segments in patients with DM, 199 of $15664(1.3 \%)$ in patients without DM, p<0.001).

Accordingly, the distribution of plaque types differed between DM and non-DM: mixed plaques $(13.3 \%$ vs $9.2 \%, \mathrm{p}<0.001)$, calcified plaques $(2.0 \%$ vs $1.3 \%$, $\mathrm{p}=0.015)$, and non-calcified plaques $(1.4 \%$ vs $0.8 \%$, $\mathrm{p}=0.023)$. Patients with DM showed significantly more affected segments than patients without DM in the RCA (4.4\% vs $2.7 \%, \mathrm{p}<0.001)$, LAD (7.3\% vs $5.6 \%, \mathrm{p}=0.012)$, and RCX $(3.8 \%$ vs $2.1 \%, \mathrm{p}<0.001)$.

\section{Subgroup analysis for duration of DIM}

Table 4 shows the subgroup analysis for duration of DM in the per segment analysis. Duration of DM was categorized into two groups $(<5 ;>5$ years $)$. Although patients suffering from DM for more than 5 years had a higher percentage of involvement of the distal segments $(11.2 \%$ vs $7.8 \%, \mathrm{p}=0.030)$, duration of diabetes had minimal impact on total number of segments with plaque, number of obstructive lesions, and morphology of plaques.

\section{DISCUSSION}

In the present study, differences in characteristics of CAD between patients with and without DM were detected by means of CCTA. A significant, positive correlation between the presence of $\mathrm{DM}$ and total number of segments with plaque was demonstrated. Patients with DM had a significantly higher percentage of obstructive plaques, and this was particularly true for women. Patients suffering from DM for more than 5 years did not demonstrate more obstructive coronary disease or different plaque morphology, although more distal disease was present.

\section{Table 3 Estimates of correlation of CCTA plaque characteristics with the presence of DM}

\begin{tabular}{|c|c|c|c|c|}
\hline Variable & Univariate, parameter estimate & p Value & Multivariate, parameter estimate & p Value \\
\hline Total calcium score & 22.25 & 0.049 & 16.88 & 0.127 \\
\hline Total segments with plaque & 0.394 & 0.003 & 0.292 & 0.016 \\
\hline CAD & $1.11(0.74$ to 1.70$)$ & 0.617 & & \\
\hline Obstructive plaque & 2.32 (1.40 to 3.84$)$ & 0.001 & 2.16 (1.23 to 3.78$)$ & 0.007 \\
\hline Non-obstructive plaque & $0.67(0.43$ to 1.05$)$ & 0.078 & & \\
\hline LM (yes or no) & $1.54(0.90$ to 2.70$)$ & 0.107 & & \\
\hline RCA (yes or no) & 1.45 (0.93 to 2.60$)$ & 0.101 & & \\
\hline LAD (yes or no) & $1.22(0.81$ to 1.85$)$ & 0.337 & & \\
\hline RCX (yes or no) & 1.59 (1.01 to 2.49$)$ & 0.044 & $1.36(0.82$ to 2.26$)$ & 0.229 \\
\hline Proximal plaques & 0.142 & 0.019 & 0.089 & 0.110 \\
\hline Distal plaques & 0.253 & 0.002 & 0.203 & 0.010 \\
\hline
\end{tabular}

Data are ORs $(95 \% \mathrm{Cl})$ or estimates of correlation.

CAD, coronary artery disease; CCTA, cardiac CT coronary angiography; DM, diabetes mellitus; LAD, left anterior descending; LM, left main; $\mathrm{RCA}$, right coronary artery; RCX, ramus circumflexus. 
Table 4 Prevalence, extent, localization, and morphology of plaques - per segment analysis in subgroup duration of DM

\begin{tabular}{|c|c|c|c|}
\hline & $\begin{array}{l}\text { DM <5 years } \\
(n=53 ; 797 \\
\text { segments) }\end{array}$ & $\begin{array}{l}\text { DM >5 years } \\
(n=46 ; 683 \\
\text { segments) }\end{array}$ & p Value \\
\hline Total segments & $790(99.1)$ & $681(99.7)$ & 0.149 \\
\hline $\begin{array}{l}\text { Total segments } \\
\text { with plaque }\end{array}$ & 121 (15.3) & 125 (18.4) & 0.108 \\
\hline $\begin{array}{l}\text { Obstructive } \\
\text { plaque }\end{array}$ & $23(2.9)$ & $21(3.1)$ & 0.847 \\
\hline $\begin{array}{l}\text { Non-obstructive } \\
\text { plaque }\end{array}$ & $98(12.4)$ & $104(15.3)$ & 0.111 \\
\hline Plaque in LM & $12(1.5)$ & $6(0.9)$ & 0.267 \\
\hline Plaque in RCA & $32(4.1)$ & $32(4.7)$ & 0.544 \\
\hline Plaque in LAD & $53(6.7)$ & $55(8.1)$ & 0.316 \\
\hline Plaque in RCX & 24 (3.0) & $32(4.7)$ & 0.097 \\
\hline Proximal plaque & $59(7.5)$ & 49 (7.2) & 0.841 \\
\hline Distal plaque & $62(7.8)$ & 76 (11.2) & 0.030 \\
\hline Mixed plaque & $96(12.2)$ & 99 (14.5) & 0.179 \\
\hline Calcified plaque & $15(1.9)$ & $15(2.2)$ & 0.681 \\
\hline $\begin{array}{l}\text { Non-calcified } \\
\text { plaque }\end{array}$ & $10(1.3)$ & $11(1.6)$ & 0.573 \\
\hline
\end{tabular}

\section{Extent of CAD}

The present study showed a positive correlation between the presence of DM and the total number of segments with plaque. Patients with DM showed more affected segments than patients without DM. Higher prevalence of plaques in patients with DM has been reported in previous invasive as well as postmortem studies. Pundziute et $a l^{18}$ reported observations in 60 patients (including 19 with DM) using CCTA followed by conventional coronary angiography with intravascular ultrasound (IVUS); the authors demonstrated that patients with DM had significantly more affected segments on CCTA and with IVUS. In a postmortem study, Burke et $a l^{19}$ showed that patients with DM have a larger amount of total and distal plaques. In our study, in patients with atypical chest pain, DM was also associated with more obstructive $\mathrm{CAD}$. This is in line with an earlier study performed by Chu $e t a l^{20}$ who demonstrated more obstructive plaques in symptomatic patients with DM as compared with patients without DM (2.5 \pm 2.5 vs $1.1 \pm 1.4)$. The CAC-score in our study was higher in patients with DM, compared with patients without DM (118 \pm 270.7 vs $73.5 \pm 209.3$, $\mathrm{p}=0.049$ ). This is in line with an earlier study by de Araujo et $a l^{21}$, who showed a significant difference in (median) CAC-score between patients with atypical chest pain with and without DM $(68(0-311)$ vs $0(0-67)$, $\mathrm{p}<0.001)$. While our study looked at CAD in patients with atypical chest pain and DM, several studies have demonstrated CAD in asymptomatic patients with DM. Scholte et $a l^{22}$ revealed a high prevalence of CAD in asymptomatic patients with type $2 \mathrm{DM}$, with almost $80 \%$ showing CAD. Zeina et al also showed a higher prevalence of $\mathrm{CAD}$ in asymptomatic patients with $\mathrm{DM}$. The total CAC-score was significantly higher in patients with DM than in patients without DM $(p<0.001)$. Higher CAC-scores were present in patients with obstructive $\mathrm{CAD}^{23}$ In an earlier study, Rivera et $a l^{24}$ also demonstrated an increasing prevalence of significant stenoses with increasing CAC-scores $(\mathrm{p}<0.001)$.

The present study showed that many patients with DM already developed serious CAD at the time of examination. One explanation could be that DM had existed long before it was diagnosed, due to lack of typical symptoms of the disease, and cardiovascular damage could have developed meanwhile. ${ }^{4}$ The previously mentioned studies demonstrated this in asymptomatic patients with DM.

Furthermore, in the present study women had a higher percentage of obstructive $\mathrm{CAD}$ in the $\mathrm{DM}$ and non-DM group. This is in contrast with several previous studies with CCTA that showed more obstructive CAD in men. ${ }^{21} 25$ These apparently conflicting results might be explained by the increasing notion of, and attention to, the atypical and late presentation of cardiac symptoms in women. ${ }^{26}{ }^{27}$ On average, clinical symptoms of heart disease appear 10 years later in women than in men. ${ }^{26}$ Studies in the Women's Ischemia Syndrome Evaluation (WISE) study support the concept of a multifactorial model where sex hormones interact with traditional and novel risk factors. Especially inflammatory process biomarkers (such as $\mathrm{C}$ reactive protein), leading to an increase in the functional expression of atherosclerotic plaque and vascular or metabolic alterations result in worse outcomes for women. ${ }^{28}$ Also, medical diagnosis and treatment for stable angina is different in men and women. ${ }^{29}$ Women were less likely to be referred for testing, in particular for exercise testing and invasive angiography. Antiplatelet and statin therapies were used significantly less in women than in men at the initial assessment and at 1 year, even in those in whom CAD had been confirmed, which unfortunately influences outcome.

\section{Duration of DIM}

Previous studies have shown that the duration of type 2 DM correlates with all-cause mortality and significantly increases cardiovascular mortality. ${ }^{30} 31$ An autopsy study demonstrated an association between DM duration and the extent of atherosclerosis and myocardial lesions. ${ }^{32}$ Clarkson $e$ t $a l^{33}$ showed that vascular reactivity, a marker of impaired endothelial dysfunction, is impaired in patients with long-term type $1 \mathrm{DM}$. Also the degree of impairment is related to the duration of DM. Thus, one may speculate that longer exposure to hyperglycemia may increase the risk of endothelial dysfunction and thus increase the risk of developing CAD. To the best of our knowledge, no studies researched the correlation between the duration of DM and distal plaques. In our study, we found that patients suffering from DM for more than 5 years have more distal plaques, although 
they did not demonstrate more obstructive coronary disease or different plaque morphology. Patients suffering from DM for a prolonged period will have more extensive and widespread disease.

\section{Radiation dose CCTA}

Bell $e t a b^{34}$ showed in a prospective study that iodinated contrast, $\beta$-blockers, and nitroglycerin as part of a predefined CCTA protocol are safe and associated with a low rate of adverse events. In the past decade, studies have focused on radiation dose-reduction techniques with CCTA. The latest generation CCTA scanners can provide an effective dose below $1.0 \mathrm{mSv}^{7}$ In comparison, patient dose is typically $2.4 \mathrm{mSv}$ for a ${ }^{13} \mathrm{NH}_{3}$ positron emission tomography scan, $2.5-5 \mathrm{mSv}$ for diagnostic invasive selective coronary angiography, and $5-16 \mathrm{mSv}$ for nuclear myocardial perfusion imaging by means of single photon emission CT. ${ }^{35-37}$ Safety and low radiation exposure with a high negative predictive value makes CCTA a very appropriate imaging technique for the exclusion of CAD in symptomatic patients and perhaps even as a presymptomatic screening tool. The radiation dose of CCTA in this study is higher in patients with DM compared with patients without DM. This difference could be explained by the fact that patients with DM are more obese compared with patients without DM. Obese patients require a higher tube voltage $(\mathrm{kV})$ and current (mAs) to produce a diagnostic CCTA, which leads to a higher radiation dose.

\section{Clinical implication}

The combination of CAD and DM strongly increases cardiovascular mortality. ${ }^{30} 31$ The present study showed that a clinically significant number of patients with atypical chest pain and DM already had developed (serious) $\mathrm{CAD}$ at the time of first examination. Previous studies with asymptomatic patients also demonstrated a higher prevalence $(80-93 \%)$ of CAD in patients with DM. ${ }^{22-23}$ There is extensive evidence of prognostic information using CAC-score in symptomatic and asymptomatic patients. ${ }^{38}$ However, the additional value of performing CCTA in these patients has been a matter of debate. In the CONFIRM registry, CCTA was unable to predict death of non-fatal MI in 7500 patients. ${ }^{39}$ Nonetheless, in symptomatic patients the incremental prognostic value of CCTA has been established. ${ }^{40}$ The best CCTA parameter for prediction of mortality was the number of proximal segments with mixed or calcified plaques. ${ }^{41}$ Thus, CCTA is useful in detection of CAD in patients with DM, either with or without symptoms of atypical chest pain. The high diagnostic yield in symptomatic patients with DM may justify the use of CCTA in daily clinical practice and can be considered as a criterion for appropriate use. Since prognostic value of performing CCTA in asymptomatic patients is unclear, further prospective studies are needed.

\section{Limitations}

Several limitations should be mentioned. First, this is a single-center study with a medium-size cohort in which the percentage of patients with DM was relatively small. Also, the examinations were performed at a single time point. There were some differences in the baseline characteristics of the two subgroups of patients, like obesity, and medication use, that could have contributed to the higher disease extent observed in patients with DM. Nevertheless, after adjusting for those differences, DM remained an independent predictor of plaque burden and obstructive CAD. Since patients referred for CCTA were suffering from atypical chest pain, but had no history of clinically diagnosed CAD, a potential referral bias has to be taken into account. In addition, limitations of CCTA in general should be mentioned; the presence of ischemia cannot be determined on CCTA, and abnormal CCTA findings should ideally be combined with functional data.

\section{CONCLUSIONS}

Although the prevalence of CAD in patients with atypical chest pain and DM did not differ from that in non-DM, patients with $\mathrm{DM}$ with $\mathrm{CAD}$ had more advanced CAD than patients without DM. They showed more affected coronary segments and more obstructive CAD than patients without DM; the latter especially in women with DM. Duration of DM ( $>5$ years), in our study population, was not associated with more obstructive coronary disease or a different plaque morphology, although more distal disease was present.

Contributors MMGK and KB researched data and wrote the manuscript. RJJK researched data and reviewed/edited the manuscript. ACvR reviewed/edited the manuscript. PK and JHC contributed to the discussion and reviewed/ edited the manuscript. FMvdZ researched data, contributed to the discussion, and reviewed/edited the manuscript

Funding This research received no specific grant from any funding agency in the public, commercial or not-for-profit sectors.

\section{Competing interests None.}

Ethics approval The patients were prospectively included in the study and all patients signed informed consent. All patients did sign an informed consent for usage of their data.

Provenance and peer review Not commissioned; externally peer reviewed.

Data sharing statement No additional data are available.

Open Access This is an Open Access article distributed in accordance with the Creative Commons Attribution Non Commercial (CC BY-NC 3.0) license, which permits others to distribute, remix, adapt, build upon this work noncommercially, and license their derivative works on different terms, provided the original work is properly cited and the use is non-commercial. See: http:// creativecommons.org/licenses/by-nc/3.0/

\section{REFERENCES}

1. International Diabetes Federation. International Diabetes Federation. 2013.

2. Rana JS, Dunning A, Achenbach S, et al. Differences in prevalence, extent, severity, and prognosis of coronary artery disease among patients with and without diabetes undergoing coronary computed tomography angiography: results from 10,110 individuals from the CONFIRM (COronary CT Angiography EvaluatioN For Clinical 
Outcomes): an InteRnational Multicenter Registry. Diabetes Care 2012;35:1787-94.

3. Goraya TY, Leibson CL, Palumbo PJ, et al. Coronary atherosclerosis in diabetes mellitus: a population-based autopsy study. J Am Coll Cardiol 2002;40:946-53.

4. Hu FB, Stampfer MJ, Haffner SM, et al. Elevated risk of cardiovascular disease prior to clinical diagnosis of type 2 diabetes. Diabetes Care 2002;25:1129-34.

5. Petcherski O, Gaspar T, Halon DA, et al. Diagnostic accuracy of 256-row computed tomographic angiography for detection of obstructive coronary artery disease using invasive quantitative coronary angiography as reference standard. Am J Cardiol 2013;111:510-15.

6. Taylor AJ, Cerqueira M, Hodgson JM, et al. ACCF/SCCT/ACR/AHA ASE/ASNC/NASCI/SCAI/SCMR 2010 appropriate use criteria for cardiac computed tomography. A report of the American College of Cardiology Foundation Appropriate Use Criteria Task Force, the Society of Cardiovascular Computed Tomography, the American College of Radiology, the American Heart Association, the American Society of Echocardiography, the American Society of Nuclear Cardiology, the North American Society for Cardiovascular Imaging, the Society for Cardiovascular Angiography and Interventions, and the Society for Cardiovascular Magnetic Resonance. J Am Coll Cardiol 2010;56:1864-94.

7. Achenbach S, Marwan M, Ropers D, et al. Coronary computed tomography angiography with a consistent dose below $1 \mathrm{mSv}$ using prospectively electrocardiogram-triggered high-pitch spiral acquisition. Eur Heart J 2010;31:340-6.

8. American Diabetes Association. Diagnosis and classification of diabetes mellitus. Diabetes Care 2009;32(Suppl 1):S62-7.

9. Wasfy MM, Brady TJ, Abbara S, et al. Comparison of the Diamond-Forrester method and Duke Clinical Score to predict obstructive coronary artery disease by computed tomographic angiography. Am J Cardiol 2012;109:998-1004.

10. Diamond GA, Forrester JS. Probability of CAD. Circulation 1982;65:641-2.

11. Taylor AJ, Bindeman J, Feuerstein I, et al. Coronary calcium independently predicts incident premature coronary heart disease over measured cardiovascular risk factors: mean three-year outcomes in the Prospective Army Coronary Calcium (PACC) project. J Am Coll Cardiol 2005;46:807-14.

12. European Society of Hypertension-European Society of Cardiology Guidelines Committee. 2003 European Society of HypertensionEuropean Society of Cardiology guidelines for the management of arterial hypertension. J Hypertens 2003;21:1011-53.

13. Expert Panel on Detection, Evaluation, and Treatment of High Blood Cholesterol in Adults. Executive Summary of The Third Report of The National Cholesterol Education Program (NCEP) Expert Panel on Detection, Evaluation, and Treatment of High Blood Cholesterol in Adults (Adult Treatment Panel III). JAMA 2001;285:2486-97.

14. Lee KH, Lee JM, Moon SK, et al. Attenuation-based automatic tube voltage selection and tube current modulation for dose reduction at contrast-enhanced liver CT. Radiology 2012;265:437-47.

15. Agatston AS, Janowitz WR, Hildner FJ, et al. Quantification of coronary artery calcium using ultrafast computed tomography. J Am Coll Cardiol 1990;15:827-32.

16. Raff GL, Abidov A, Achenbach S, et al. SCCT guidelines for the interpretation and reporting of coronary computed tomographic angiography. J Cardiovasc Comput Tomogr 2009;3:122-36.

17. Leber AW, Knez A, Becker A, et al. Accuracy of multidetector spiral computed tomography in identifying and differentiating the composition of coronary atherosclerotic plaques: a comparative study with intracoronary ultrasound. J Am Coll Cardiol 2004;43:1241-7.

18. Pundziute G, Schuijf JD, Jukema JW, et al. Type 2 diabetes is associated with more advanced coronary atherosclerosis on multislice computed tomography and virtual histology intravascular ultrasound. J Nucl Cardiol 2009;16:376-83.

19. Burke AP, Kolodgie FD, Zieske A, et al. Morphologic findings of coronary atherosclerotic plaques in diabetics: a postmortem study. Arterioscler Thromb Vasc Biol 2004;24:1266-71.

20. Chu ZG, Yang ZG, Dong ZH, et al. Comparative analysis of coronary artery disease assessed by coronary CT angiography between patients with type 2 diabetes mellitus and non-diabetic patients. Int J Cardiol 2011;147:178-81.

21. de Araujo GP, Garcia-Garcia HM, Carvalho MS, et al. Diabetes as an independent predictor of high atherosclerotic burden assessed by coronary computed tomography angiography: the coronary artery disease equivalent revisited. Int $J$ Cardiovasc Imaging 2012;29:1105-14.

22. Scholte AJ, Schuijf JD, Kharagjitsingh AV, et al. Prevalence of coronary artery disease and plaque morphology assessed by multi-slice computed tomography coronary angiography and calcium scoring in asymptomatic patients with type 2 diabetes. Heart 2008;94:290-5

23. Zeina AR, Odeh M, Rosenschein U, et al. Coronary artery disease among asymptomatic diabetic and nondiabetic patients undergoing coronary computed tomography angiography. Coron Artery Dis 2008;19:37-41.

24. Rivera JJ, Nasir K, Choi EK, et al. Detection of occult coronary artery disease in asymptomatic individuals with diabetes mellitus using non-invasive cardiac angiography. Atherosclerosis 2009;203:442-8.

25. Qureshi W, Blaha MJ, Nasir K, et al. Gender differences in coronary plaque composition and burden detected in symptomatic patients referred for coronary computed tomographic angiography. Int $J$ Cardiovasc Imaging 2013;29:463-9.

26. McSweeney JC, Cody M, O'Sullivan P, et al. Women's early warning symptoms of acute myocardial infarction. Circulation 2003;108:2619-23.

27. Goldberg RJ, O'Donnell C, Yarzebski J, et al. Sex differences in symptom presentation associated with acute myocardial infarction: a population-based perspective. Am Heart J 1998:136:189-95.

28. Shaw LJ, Bairey Merz CN, Pepine CJ, et al. Insights from the NHLBI-Sponsored Women's Ischemia Syndrome Evaluation (WISE) Study: part I: gender differences in traditional and novel risk factors, symptom evaluation, and gender-optimized diagnostic strategies. J Am Coll Cardiol 2006;47:S4-20.

29. Daly C, Clemens F, Lopez Sendon JL, et al. Gender differences in the management and clinical outcome of stable angina. Circulation 2006;113:490-8.

30. Silbernagel G, Rosinger S, Grammer TB, et al. Duration of type 2 diabetes strongly predicts all-cause and cardiovascular mortality in people referred for coronary angiography. Atherosclerosis 2012;221:551-7.

31. Fox CS, Sullivan L, D'Agostino RB Sr, et al. The significant effect of diabetes duration on coronary heart disease mortality: the Framingham Heart Study. Diabetes Care 2004;27:704-8.

32. Burchfiel CM, Reed DM, Marcus EB, et al. Association of diabetes mellitus with coronary atherosclerosis and myocardial lesions. An autopsy study from the Honolulu Heart Program. Am J Epidemiol 1993;137:1328-40.

33. Clarkson P, Celermajer DS, Donald AE, et al. Impaired vascular reactivity in insulin-dependent diabetes mellitus is related to disease duration and low density lipoprotein cholesterol levels. J Am Coll Cardiol 1996;28:573-9.

34. Bell GW, Edwardes M, Dunning AM, et al. Periprocedural safety of 64-detector row coronary computed tomographic angiography: results from the prospective multicenter ACCURACY trial. J Cardiovasc Comput Tomogr 2010:4:375-80.

35. Hoffmann U, Ferencik M, Cury RC, et al. Coronary CT angiography. J Nucl Med 2006;47:797-806.

36. Kajander $\mathrm{S}$, Ukkonen $\mathrm{H}$, Sipila $\mathrm{H}$, et al. Low radiation dose imaging of myocardial perfusion and coronary angiography with a hybrid PET/CT scanner. Clin Physiol Funct Imaging 2009;29:81-8.

37. Stabin MG. Radiopharmaceuticals for nuclear cardiology: radiation dosimetry, uncertainties, and risk. J Nucl Med 2008;49:1555-63.

38. Hecht HS, Narula J. Coronary artery calcium scanning in asymptomatic patients with diabetes mellitus: a paradigm shift. $J$ Diabetes 2012;4:342-50.

39. Cho I, Chang HJ, Sung JM, et al.; CONFIRM Investigators. Coronary computed tomographic angiography and risk of all-cause mortality and nonfatal myocardial infarction in subjects without chest pain syndrome from the CONFIRM Registry (coronary CT angiography evaluation for clinical outcomes: an international multicenter registry). Circulation 2012;126:304-13.

40. Al-Mallah MH, Qureshi W, Lin FY, et al. Does coronary CT angiography improve risk stratification over coronary calcium scoring in symptomatic patients with suspected coronary artery disease? Results from the prospective multicenter international CONFIRM registry. Eur Heart J Cardiovasc Imaging 2014; 15:267-74.

41. Nance JW Jr, Schlett CL, Schoepf UJ, et al. Incremental prognostic value of different components of coronary atherosclerotic plaque at cardiac CT angiography beyond coronary calcification in patients with acute chest pain. Radiology 2012;264:679-90. 